\title{
MD Simulated Microstructure of Liquid Sodium Alloyed with Lead
}

\author{
Inessa Yu. Shimkevich, Alexander L. Shimkevich \\ National Research Center "Kurchatov Institute", Moscow, Russian Federation \\ Email: shimkevich_al@nrcki.ru
}

Received 31 March 2014; revised 3 May 2014; accepted 5 June 2014

Copyright (C) 2014 by authors and Scientific Research Publishing Inc.

This work is licensed under the Creative Commons Attribution International License (CC BY). http://creativecommons.org/licenses/by/4.0/

\section{c) (7) Open Access}

\begin{abstract}
The results of molecular-dynamics (MD) simulation are obtained for structural and thermodynamic properties of the molten system, $\mathrm{Na}_{1-x} \mathrm{~Pb}_{x}(x \leq 0.1)$, at $698 \mathrm{~K}$ in the model of nearly free electronic gas (NFE approximation). The all numerical experiments are carried out by unified procedure: 1) equilibrating the MD cell $1 \mathrm{ps} ; 2)$ calculating partial radial distribution functions $g_{\alpha \beta}(r)$ in 1,5 , and $\left.10 \mathrm{ps} ; 3\right)$ data handling for calculating other characteristics. It follows from this that lead impurity in liquid sodium at concentration in the range of $1 \%-10 \%$ is characterized by micro-heterogenetic structure in the form of cluster compounds with variable composition. Just therefore the sodium alloys, $\mathrm{Na}-\mathrm{M}_{\mathrm{IV}}$, with four-group elements of Periodic table have no eutectic in this range of additive concentrations. This eutectic is needed for modifying sodium coolant of the fast nuclear reactor. Therefore it is reasonable to find an alternative alloy of sodium with additive from adjacent groups which has a eutectic in this range of concentrations, for example, the eutectic, $\mathrm{Na}_{0.929} \mathrm{Tl}_{0.071}$, with melting point of $64^{\circ} \mathrm{C}$. The modified sodium coolant by isotope, ${ }^{205} \mathrm{Tl}$, can appear attractive for inhibiting the chemical activity of sodium just as the lead alloyed one.
\end{abstract}

\section{Keywords}

Molecular Dynamics, Liquid Sodium, Lead and Thallium Additives, Micro-Heterogeneous Alloys

\section{Introduction}

A non-ideal solution of lead in liquid sodium takes place in the whole range of $\mathrm{Na}-\mathrm{Pb}$ alloy composition but the strongest effects are observed nearby $20 \%$ and $50 \%$ of lead concentration [1]-[3] due to existence of clusters, $\left(\mathrm{Na}_{4} \mathrm{~Pb}\right)_{\mathrm{n}}$ and $(\mathrm{NaPb})_{\mathrm{m}}$, in the alloy. The first kind of clusters is set conditions for existing of the compound, $\mathrm{Na}_{15} \mathrm{~Pb}_{4}$, in this system and managing the liquid-alloy microstructure in the phase diagram nearby sodium.

This effect is disclosed in analyzing the structural factors, $S_{N N}(q), S_{N C}(q)$, and $S_{C C}(q)$, calculated on various 
models [2] [4] [5] and by a sharp change of the alloy entropy [1] or an increase of the alloy electric resistance [3] [6] as well as a deviation of alloy composition fluctuations from the ideal mixture as a function of $S_{C C}(q)_{q \rightarrow 0}$ depending on the composition of the $\mathrm{Na}-\mathrm{Pb}$ alloy [2].

In that case, the cluster model is the most realistic for considering the $\mathrm{Na}-\mathrm{Pb}$ alloy in the range of composition nearby sodium. Therefore, a new molecular-dynamic (MD) studying of its microstructure and atomic dynamics with small additive of lead can be useful to develop a concept for composition improving the sodium coolant in particular inhibiting its chemical activity and an automatic shut-down of sodium fires in the environment. This is obtained by protecting effect of lead-sodium clusters [7]-[9]. At the same time, it is necessary to have eutectic of sodium with this inhibitive additive for stabilizing the coolant composition [7] [9]. That is why we are seeking eutectic in the alloy, $\mathrm{Na}_{1-x} \mathrm{~Pb}_{x}$ at $x \leq 0.1$ [8] [10].

MD simulating structural and thermodynamic properties of liquid alloy, $\mathrm{Na}_{1-\chi} \mathrm{Pb}_{x}(x \leq 0.1)$ at $698 \mathrm{~K}$ are studied in the model of nearly-free electronic gas (NFE approximation) [11] [12] allowing to use local potentials for calculating atomic interaction.

\section{Paired Interaction Potentials of Sodium and Lead Particles}

In the linear approximation of free-electron-gas density, $n_{e}^{\alpha \beta}$, as a function of lead content in the molten alloy, $\mathrm{Na}-\mathrm{Pb}$, it is possible to present their pair potentials in the form

$$
U_{\alpha \beta}(r)=\frac{Z_{\alpha} Z_{\beta} e^{2}}{r}+\frac{\Omega}{\pi^{2}} \int_{0}^{\infty} q^{2} \frac{\Omega q^{2}}{8 \pi^{2} e^{2}}\left(\frac{1}{\varepsilon(q)}-1\right)\left|V_{b}^{\alpha}(q) \cdot V_{b}^{\beta}(q)\right| \frac{\sin (q r)}{q r} \mathrm{~d} q .
$$

Here, $Z_{\alpha}$ and $Z_{\beta}$ are charges of the alloy ions; $V_{b}^{\alpha}(q)$ and $V_{b}^{\beta}(q)$ are the form-factors of their pseudo-potentials. The dielectric function, $\varepsilon(q)$, of the electron gas is given by Lindhard relation

$$
\varepsilon(q)=1-\frac{v_{c}(q) X(q)}{1+G(q) v_{c}(q) X(q)}
$$

where $v_{e}(q)=4 \pi e^{2} / q^{2}$ and the function of electronic polarization, $X(q)$, has the form

$$
X(q)=-\frac{m_{e} q_{F}^{\alpha \beta}}{\pi^{2} \hbar^{2}}\left[\frac{1}{2}+\frac{4\left(q_{F}^{\alpha \beta}\right)^{2}-q^{2}}{8 q q_{F}^{\alpha \beta}} \ln \left|\frac{2 q_{F}^{\alpha \beta}+q}{2 q_{F}^{\alpha \beta}-q}\right|\right],
$$

and is defined by numerical density of ions, $n^{\alpha \beta}=N / \Omega^{\alpha \beta}$ [12]-[14], average electron density, $n_{e}^{\alpha \beta}=Z^{\alpha \beta} n^{\alpha \beta}$, of the melt; its average valence, $Z^{\alpha \beta}=c_{\alpha} Z_{\alpha}+c_{\beta} Z_{\beta}$, with the atomic portions, $c_{\alpha}$ and $c_{\beta}$, of components, $\alpha$ and $\beta$, by Fermi coefficient, $q_{F}^{\alpha \beta}=\left(3 \pi^{2} n_{e}^{\alpha \beta}\right)^{1 / 3}$, and $G(q)$ from [15].

In Equation (1), a choice of lead potential is problematic due to fitting character of them in the classical MD simulation [16]-[19]. Therefore for a comparison, we use two lead potentials: the local Fiolhais one [20] in the version, $\mathrm{Fi}(\mathrm{I})$, with $\alpha=2.95, R=0.403$ a.u., and Heine-Abarenkov potential (HA). For sodium, we use the same Fiolhais potential but with $\alpha=3.499$ and $R=0.494$ a.u.

The files of these potentials are calculated in the range of $\left(R_{\min }^{\alpha \beta}-0.5\right)-50 \AA$ with the step $0.005 \AA$. Their minima have coordinates: $R_{\min }^{\mathrm{NaNa}} \sim 3.5 \AA, R_{\min }^{\mathrm{Napb}} \sim 3.5 \AA$, and $R_{\min }^{\mathrm{PbPb}} \sim 3.1 \AA$, from data of radial distribution function (RDF) of atoms in the melt, $\mathrm{Na}_{0.9} \mathrm{~Pb}_{0.1}$ [5]. The plots of these potentials are shown in Figure 1.

The parameters of MD calculations are collected in Table 1 . The molar volumes, $\Omega^{\alpha \beta}$, of minor lead additives are found from data [21]-[23] for the melt, $\mathrm{Na}_{1-x} \mathrm{~Pb}_{x}$, and linear approximation, $x \rightarrow 0$. The MD results are compared with experimental data of pure sodium at $T=698 \mathrm{~K}$ for density, $\rho_{\mathrm{Na}}=850.02 \mathrm{~kg} / \mathrm{m}^{3}$, and with the MD calculations for $\mathrm{Na}_{0.9} \mathrm{~Pb}_{0.1}$ [13], the ones for $\mathrm{Na}_{0.2} \mathrm{~Pb}_{0.8}$ [5], and experimental data [24] for two alloys: $\mathrm{Na}_{0.985} \mathrm{~Pb}_{0.015}$ and $\mathrm{Na}_{0.921} \mathrm{~Pb}_{0.079}$.

\section{Infotainment of Numerical Experiments}

The all numerical runs are carried out by the same procedure: 1) balancing out the ensemble of particles (1 ps); 2) calculating the pair RDF, $g_{\alpha \beta}(r)$, in the points of time: $1,5,10 \mathrm{ps}$; and 3) processing the obtained data for calcu- 


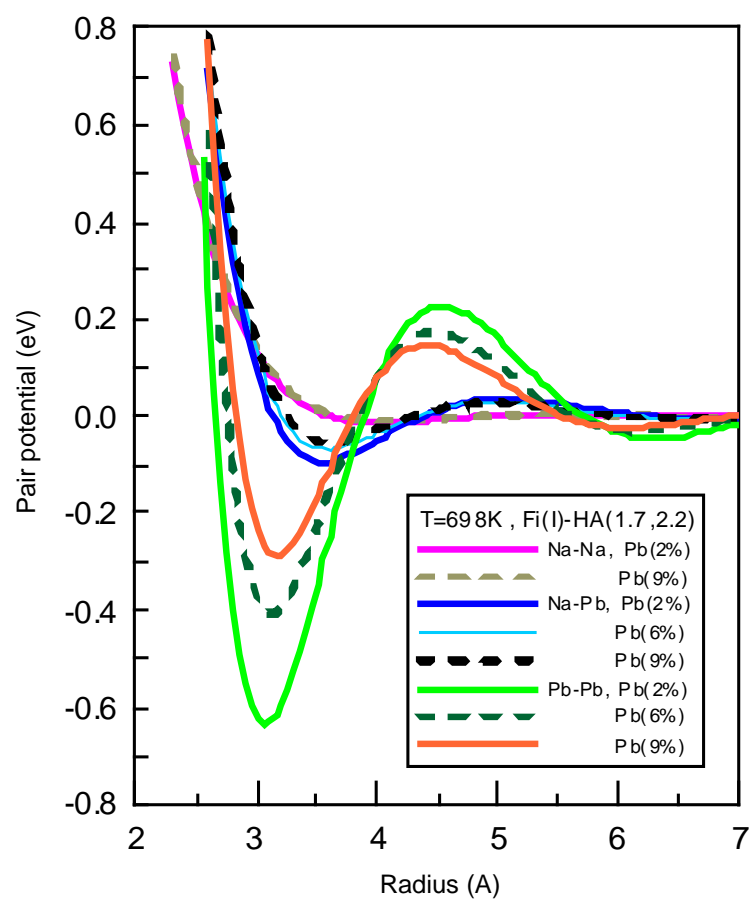

(a)

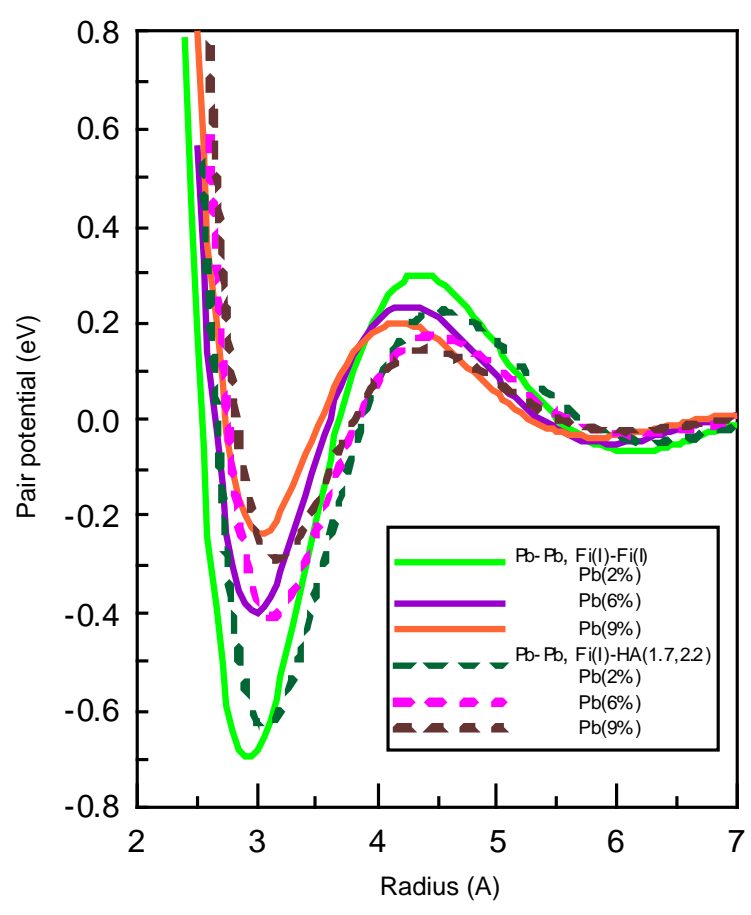

(b)

Figure 1. The plots of pair Fiolhais potential, Fi(I), for sodium, $U_{\mathrm{NaNa}}(r)$, and Heine-Abarenkov potential (HA) for lead, $U_{\mathrm{PbPb}}(r)$, as well as the mixed ones, $\mathrm{Fi}(\mathrm{I})-\mathrm{HA}$, for sodium-lead pair, $U_{\mathrm{NaPb}}(r)$ (a), the comparison of $\mathrm{Fi}(\mathrm{I})-\mathrm{Fi}(\mathrm{I})$ and $\mathrm{Fi}(\mathrm{I})-\mathrm{HA}$ for $U_{\mathrm{PbPb}}(r)(\mathrm{b})$ at three lead concentrations in liquid sodium: $2 \%, 6 \%$ and $9 \%$.

Table 1. The parameters for MD simulation of pure sodium and melt, $\mathrm{Na}_{1-x} \mathrm{~Pb}_{x}$, into the $\mathrm{MD}$ cube with the edge length, $L$, at $698 \mathrm{~K}$.

\begin{tabular}{ccccccccc}
\hline Melt & $\Omega^{\alpha \beta}$, a.u. & $L, \AA$ & $n^{\alpha \beta}, 1 / \AA^{3}$ & $N_{\mathrm{Na}}$ & $N_{\mathrm{Pb}}$ & $Z^{\alpha \beta}$ & $n_{e}^{\alpha \beta}, 1 / \AA^{3}$ & $q_{F}^{\alpha \beta}, 1 / \AA$ \\
\hline $\mathrm{Na}$ & 303.1 & 62.7 & 0.02227 & 5488 & - & 1.00 & 0.02227 & 0.8703 \\
$\mathrm{Na}_{0.98} \mathrm{~Pb}_{0.02}$ & 298.5 & 94.2 & 0.02261 & 18522 & 378 & 1.06 & 0.02397 & 0.8920 \\
$\mathrm{Na}_{0.975} \mathrm{~Pb}_{0.025}$ & 297.3 & 89.8 & 0.02270 & 16000 & 410 & 1.08 & 0.02440 & 0.8973 \\
$\mathrm{Na}_{0.97} \mathrm{~Pb}_{0.03}$ & 296.2 & 89.8 & 0.02279 & 16000 & 495 & 1.09 & 0.02484 & 0.9026 \\
$\mathrm{Na}_{0.96} \mathrm{~Pb}_{0.04}$ & 293.8 & 90.3 & 0.02296 & 16000 & 667 & 1.12 & 0.02572 & 0.9132 \\
$\mathrm{Na}_{0.95} \mathrm{~Pb}_{0.05}$ & 291.5 & 89.9 & 0.02315 & 16000 & 842 & 1.15 & 0.02662 & 0.9237 \\
$\mathrm{Na}_{0.94} \mathrm{~Pb}_{0.06}$ & 289.2 & 90.0 & 0.02333 & 16000 & 1021 & 1.18 & 0.02753 & 0.9342 \\
$\mathrm{Na}_{0.93} \mathrm{~Pb}_{0.07}$ & 286.9 & 90.1 & 0.02352 & 16000 & 1204 & 1.21 & 0.02846 & 0.9445 \\
$\mathrm{Na}_{0.92} \mathrm{~Pb}_{0.08}$ & 284.6 & 90.2 & 0.02371 & 16000 & 1391 & 1.24 & 0.02940 & 0.9548 \\
$\mathrm{Na}_{0.91} \mathrm{~Pb}_{0.09}$ & 282.3 & 90.3 & 0.02390 & 16000 & 1583 & 1.27 & 0.03036 & 0.9651 \\
\hline
\end{tabular}

lating the following characteristics.

1) Average kinetic, $E_{\text {kin }}^{\alpha}\left(t_{i}\right)$, potential, $E_{\text {pot }}^{\alpha}\left(t_{i}\right)$, and total, $E_{\text {tot }}^{\alpha}\left(t_{i}\right)$, energy of $\alpha$ particles in the point of time, $t_{i}$, and a pressure of the system defined by the virial equation

$$
3 P V=2 E_{\mathrm{kin}}-\sum_{i=1}^{N-1} \sum_{j \geq i}^{N} r_{i j} \frac{\mathrm{d} U\left(r_{i j}\right)}{\mathrm{d} r} .
$$

2) Partial RDF, $g_{\mathrm{NaNa}}(r), g_{\mathrm{NaPb}}(r)$, and $g_{\mathrm{PbPb}}(r)$, the average weighted ones, $g(r)$ and $N(r)$, structure factor, $S(q)$, taking into account the atomic density of components: $n_{\mathrm{Na}}=N_{\mathrm{Na}} / V, n_{\mathrm{Pb}}=N_{\mathrm{Pb}} / V$, at $\bar{n}=n_{\mathrm{Na}}+n_{\mathrm{Pb}}$ and neutron scattering lengths, $b_{\mathrm{Na}}, b_{\mathrm{Pb}}$ : 


$$
g(r)=W_{\mathrm{NaNa}} g_{\mathrm{NaNa}}(r)+W_{\mathrm{NaPb}} g_{\mathrm{NaPb}}(r)+W_{\mathrm{PbPb}} g_{\mathrm{PbPb}}(r),
$$

where $W_{a b}=n_{a} b_{a} n_{b} b_{b} /\left(n_{\mathrm{Na}} b_{\mathrm{Na}}+n_{\mathrm{Pb}} b_{\mathrm{Pb}}\right)^{2}$;

$$
\begin{gathered}
N(r)=4 p r^{2}\left[g(r)+W_{\mathrm{NaPb}} g_{\mathrm{NaPb}}(r)\right], \\
S(q)=\sum_{\alpha, \beta} b_{\alpha} b_{\beta} \sqrt{n_{\alpha} n_{\beta}} S_{\alpha \beta}(q) /\left(n_{\mathrm{Na}} b_{\mathrm{Na}}^{2}+n_{\mathrm{Pb}} b_{\mathrm{Pb}}^{2}\right) .
\end{gathered}
$$

Here, $S_{\alpha \beta}(q)$ is the partial structure factor as

$$
S_{a b}(q)=\delta_{a b}+\left(\rho_{a} \rho_{b}\right)^{1 / 2} \int_{0}^{\infty} 4 \pi r^{2}\left[g_{\alpha \beta}(r)-1\right] \frac{\sin (q r)}{q r} \mathrm{~d} r,
$$

with $\delta_{\alpha \beta}$ as Christoffel criterion equal to 1 at $a=b$ and 0 at $a \neq b$.

3) Correlative Bhatia-Thornton function, $g_{N N}(r)$, is for studying density fluctuations of the binary melt independently of its constituents, another one, $g_{C C}(r)$, is for studying composition fluctuations of the melt and $g_{N C}(r)$ is for studying cross-correlations between these fluctuations:

$$
\left.\begin{array}{l}
g_{N N}(r)=c_{\mathrm{Na}}^{2} g_{\mathrm{NaNa}}(r)+c_{\mathrm{Pb}}^{2} g_{\mathrm{PbPb}}(r)+2 c_{\mathrm{Na}} c_{\mathrm{Pb}} g_{\mathrm{NaPb}}(r) \\
g_{\mathrm{CC}}(r)=c_{\mathrm{Na}}^{2} c_{\mathrm{Pb}}^{2}\left[g_{\mathrm{NaNa}}(r)+g_{\mathrm{PbPb}}(r)-2 g_{\mathrm{NaPb}}(r)\right] \\
g_{N C}(r)=c_{\mathrm{Na}} c_{\mathrm{Pb}}\left[c_{\mathrm{Na}} g_{\mathrm{NaNa}}(r)-\left(c_{\mathrm{Na}}-c_{\mathrm{Pb}}\right) g_{\mathrm{NaPb}}(r)-c_{\mathrm{Pb}} g_{\mathrm{PbPb}}(r)\right]
\end{array}\right\}
$$

and the corresponding structure factors are

$$
\left.\begin{array}{l}
S_{N N}(q)=c_{\mathrm{Na}} S_{\mathrm{NaNa}}(q)+c_{\mathrm{Pb}} S_{\mathrm{PbPb}}(q)+2\left(c_{\mathrm{Na}} c_{\mathrm{Pb}}\right)^{1 / 2} S_{\mathrm{NaPb}}(q) \\
S_{C C}(q)=c_{\mathrm{Na}} c_{\mathrm{Pb}}\left[c_{\mathrm{Pb}} S_{\mathrm{NaNa}}(q)+c_{\mathrm{Na}} S_{\mathrm{PbPb}}(q)-2\left(c_{\mathrm{Na}} c_{\mathrm{Pb}}\right)^{1 / 2} S_{\mathrm{NaPb}}(q)\right] \\
S_{N C}(q)=c_{\mathrm{Na}} c_{\mathrm{Pb}}\left[S_{\mathrm{NaNa}}(q)-S_{\mathrm{PbPb}}(q)+\left(\left(c_{\mathrm{Pb}} / c_{\mathrm{Na}}\right)^{1 / 2}-\left(c_{\mathrm{Na}} / c_{\mathrm{Pb}}\right)^{1 / 2}\right) S_{\mathrm{NaPb}}(q)\right]
\end{array}\right\} .
$$

Finally, the structure factor, $S(q)$, weighted by neutron scattering lengths, $b_{\mathrm{Na}}, b_{\mathrm{Pb}}$, and by component concentrations, $c_{\mathrm{Na}}, c_{\mathrm{Pb}}$, is defined as

$$
S(q)=\left[\langle b\rangle^{2} S_{N N}(q)+2\langle b\rangle \Delta b S_{N C}(q)+(\Delta b)^{2} S_{C C}(q)\right] /\left\langle b^{2}\right\rangle,
$$

where $\langle b\rangle=c_{\mathrm{Na}} b_{\mathrm{Na}}+c_{\mathrm{Pb}} b_{\mathrm{Pb}},\left\langle b^{2}\right\rangle=c_{\mathrm{Na}} b_{\mathrm{Na}}^{2}+c_{\mathrm{Pb}} b_{\mathrm{Pb}}^{2}, \Delta b=b_{\mathrm{Na}}-b_{\mathrm{Pb}}$.

4) The bound, $S_{C C}(q \rightarrow 0)$, of structural factor of root-mean-square fluctuations in the melt equal to $S_{C C}(0)=N\left\langle(\Delta c)^{2}\right\rangle$ allows to investigate its topology [7] [12] [13]:

$$
\left.\begin{array}{l}
S_{N N}(0)=\frac{N}{V} k_{B} T \chi_{T}+\delta^{2} S_{C C}(0) \\
S_{N C}(0)=-\delta S_{C C}(0)
\end{array}\right\} .
$$

Here, the loosing coefficient is $\delta=-S_{N C}(0) / S_{C C}(0)$.

5) The isothermal coefficient of the melt compressibility is

$$
\chi_{T}=\left[S_{N N}(0)-\delta^{2} S_{C C}(0)\right] V / N k_{B} T
$$

and the module of all-round compression

$$
B_{l w}=1 / \chi_{T}=-V\left(\frac{\partial P}{\partial V}\right)_{T}
$$

6) The full coordination number, $Z_{\text {tot }}$, at the coordinate, $R_{\min }^{1}$, of the first RDF minimum is

$$
Z_{\mathrm{tot}}=\sum_{\alpha \beta} \frac{c_{\beta} b_{\alpha} b_{\beta}}{\langle b\rangle^{2}} Z_{\mathrm{min}}^{\alpha \beta}
$$


where $Z_{\min }^{\alpha \beta}=n_{\beta} \int_{0}^{R_{\min }^{1}} 4 \pi r^{2} g_{\alpha \beta}(r) \mathrm{d} r$ and Warren-Cowley coordination number [12] [13] is:

$$
a_{\mathrm{w}}=Z_{C C} / Z_{\mathrm{w}}
$$

Here, $\quad Z_{\mathrm{CC}}=c_{\mathrm{Pb}}\left(Z_{\mathrm{NaNa}}-Z_{\mathrm{PbNa}}\right)+c_{\mathrm{Na}}\left(Z_{\mathrm{PbPb}}-Z_{\mathrm{NaPb}}\right)$ and $Z_{\mathrm{W}}=c_{\mathrm{Pb}}\left(Z_{\mathrm{NaNa}}+Z_{\mathrm{NaPb}}\right)+c_{\mathrm{Na}}\left(Z_{\mathrm{PbPb}}+Z_{\mathrm{PbNa}}\right)$. If $\alpha_{\mathrm{w}}>0$, the melt is preferably homogeneous one and it is heterogeneous at $\alpha_{\mathrm{w}}<0$ for any binary system.

The MD simulation results presented below are the averaged data obtained by 5 and 10 ps of numerical exposition of binary system, $\mathrm{Na}-\mathrm{Pb}$.

\section{Results of MD Simulating the Melt, $\mathrm{Na}_{1-x} \mathrm{~Pb}_{x}(x \leq 0.1)$}

Heine-Abarenkov potential (HA) for lead, $U_{\mathrm{PbPb}}$, is softer and makes the potential well wider than the more rigid Fiolhais potential, Fi(I) (see Figure 1(b)). Increasing the content of lead in liquid sodium practically does not influence on $\mathrm{Fi}(\mathrm{I})$ potential for sodium, $U_{\mathrm{NaNa}}$, but strengthens $U_{\mathrm{PbPb}}$ and $U_{\mathrm{NaPb}}$ as it is shown in Figure 1(a). One can see that $U_{\mathrm{PbPb}}(r)$ has a deep minimum in comparison with $U_{\mathrm{NaNa}}(r)$ and $U_{\mathrm{NaPb}}(r)$. It causes clustering lead particles into liquid sodium with forming an addition solution of nanoparticles, $\mathrm{Na}_{15} \mathrm{~Pb}_{4}$, [9] in broad varying the composition of $\mathrm{Na}-\mathrm{Pb}$ alloy in sodium side of the phase diagram that is proven by the MD simulated concentration dependence of the system specific potential energy shown in Figure 2. It is insignificantly decreased with increasing lead concentration and achieves a hardly noticeable minimum at $5 \%$ of lead in liquid sodium. Then, it monotonously grows with increasing lead concentration, i.e. it doesn't disclose features for polymorphic changing the liquid matrix attached to eutectic [10]. At the same time, a static pressure in the MD cell of binary melt, $\mathrm{Na}-\mathrm{Pb}$, is changed considerably $( \pm 15 \%)$ in a complicated manner showing, at least, two conjugated minima in a point neighborhood of $5 \%$ and $8 \%$ of lead content, as shown in Figure 3.

One can see that the micro-structural transformation of $\mathrm{Na}_{1-x} \mathrm{~Pb}_{x}$ alloy at $x \sim 6 \%$ is more complicated than the simple model of reformation of clusters (the red dotted line). An apparent minimum of pressure near $5 \%$ of lead content indicates to partial ordering the melt due to cluster growth up to their subsequent reformation into the binary system, Na-Pb. It is proven by results of calculating a Warren-Cowley coordination number (16) presented in Figure 4. It is seen that the melt particles are ordered in liquid sodium when lead concentration is in two intervals (3\% - 5\%) and (7\% - 9\%). It is illustrated by a quasi-peritectic at $~ 10 \%$ and a compound at $~ 20 \%$ of lead in the liquidus of the system, Pb-Na [25] shown by the phase diagram in Figure 5.

Thus, the $5 \%$ and $9 \%$-solutions of lead in liquid sodium can be considered as a modified sodium coolant being micro-non-homogeneous that is important for auto-quenching sodium fires. Taking into account the minimum of specific potential energy at $x \sim 0.05$ (see Figure 2), one is to prefer the melt, $\mathrm{Na}_{0.95} \mathrm{~Pb}_{0.05}$, as an advanced coolant for fast reactors.

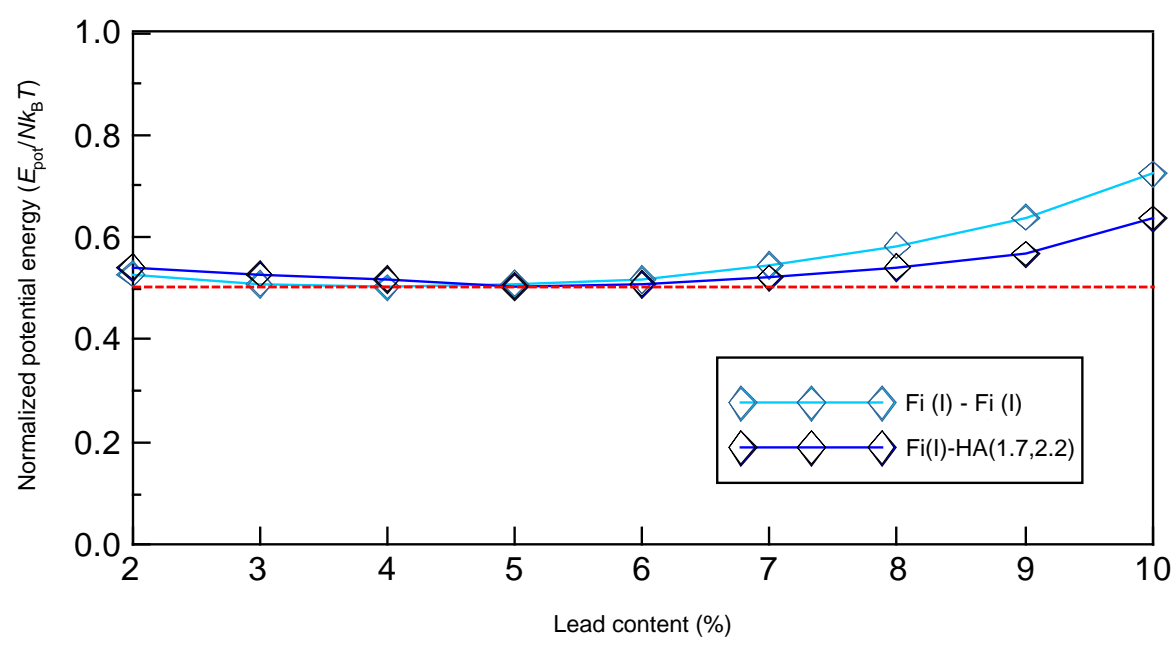

Figure 2. Normalized potential energy, $E_{\mathrm{pot}} / N k_{\mathrm{B}} T$, of liquid $\mathrm{Na}_{1-x} \mathrm{~Pb}_{x}$ alloy as a function of lead content for two models, $\mathrm{Fi}(\mathrm{I})-\mathrm{Fi}(\mathrm{I})$ and $\mathrm{Fi}(\mathrm{I})-\mathrm{HA}$, of interaction between sodium and lead particle. 


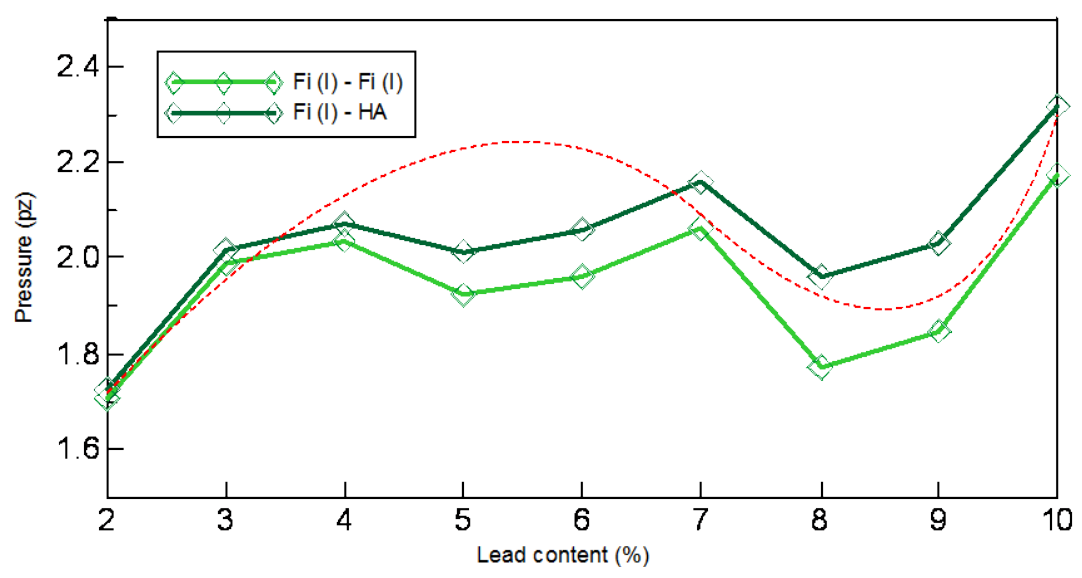

Figure 3. Plots of static pressure in the melt, $\mathrm{Na}_{1-x} \mathrm{~Pb}_{x}$, as a function of lead content for two models of sodium and lead pair potentials: $\mathrm{Fi}(\mathrm{I})-\mathrm{Fi}(\mathrm{I})$ and $\mathrm{Fi}(\mathrm{I})-\mathrm{HA}$; the red dotted line is a model for cluster reforming the alloy near $6 \%$ of lead.

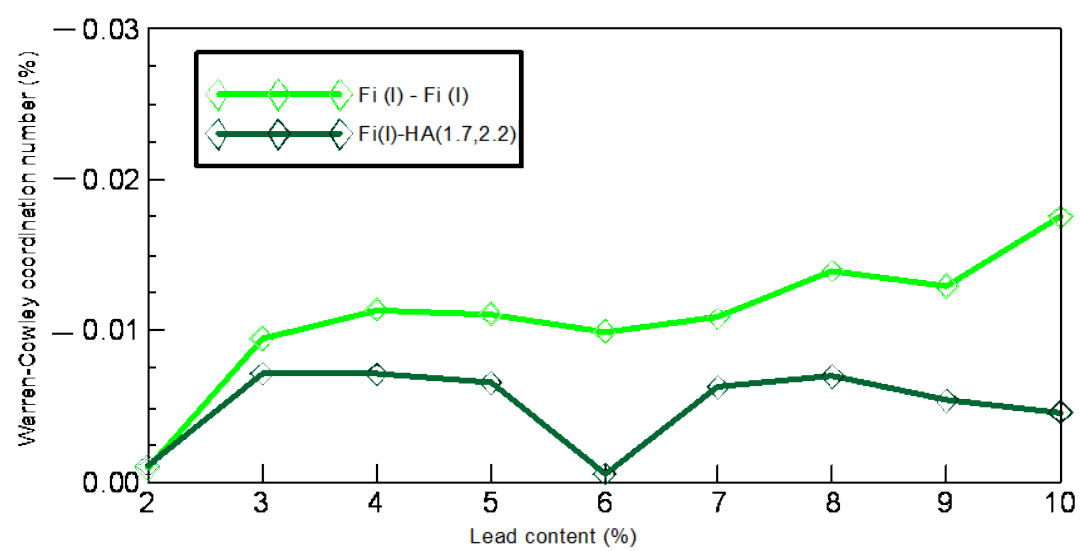

Figure 4. Plots of Warren-Cowley coordination number (16) for liquid $\mathrm{Na}_{1-x} \mathrm{~Pb}_{x}$ alloy as a function of lead concentration (\%) for two models of sodium and lead pair potentials: $\mathrm{Fi}(\mathrm{I})-\mathrm{Fi}(\mathrm{I})$ and $\mathrm{Fi}(\mathrm{I})-\mathrm{HA}$.

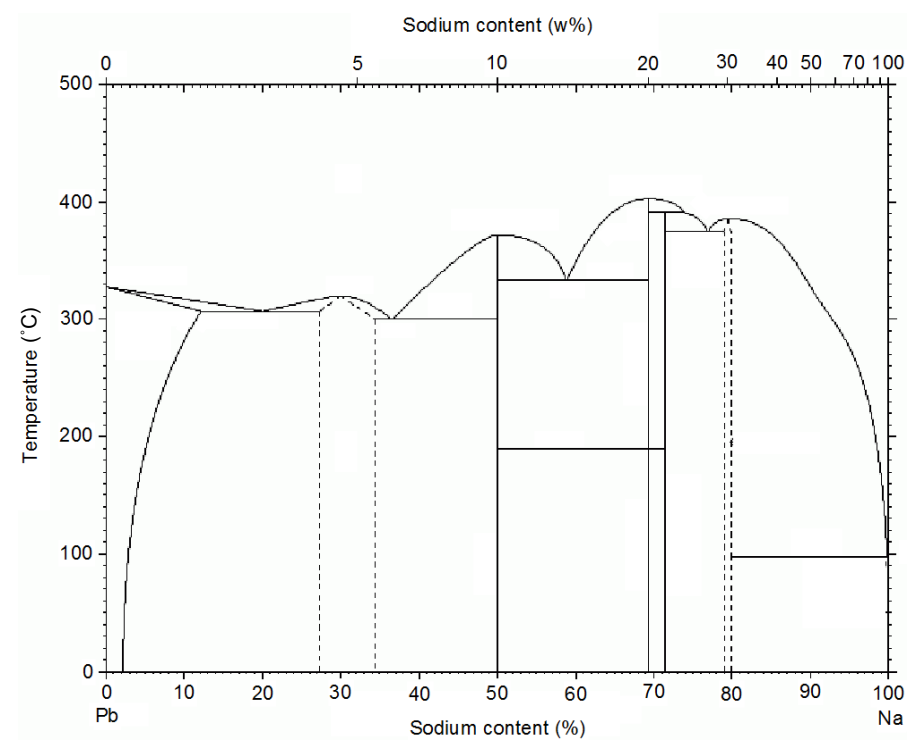

Figure 5. The phase diagram for binary system, $\mathrm{Pb}-\mathrm{Na}$ [25]. 
At the same time, the correlative Bhatia-Thornton functions (9) in the form of $g_{C C}(r)$ for the composition fluctuations of $\mathrm{Na}-\mathrm{Pb}$ melt (see Figure 6(a)) and in the form of $g_{N C}(r)$ for cross-correlations between its density and composition fluctuations of its (see Figure 6(b)) indicate to steady-state micro-heterogeneity of 9\%-lead solution in sodium. On can see that the primary coordination of like particles (positive values of $g_{C C}$ ) and unlike atoms (negative value of $g_{C C}$ ) is increased more than 1.8 times when the concentration of lead in sodium melt becomes half as much again (of $6 \%$ to $9 \%$ ) as well as a generation of micro-inclusions induced by density fluctuations of the melt (positive values of $g_{N C}$ ). Just the depth of negative $g_{C C}(r)$ and the height of positive $g_{N C}(r)$ characterize the stability of quasi-molecular clusters in liquid metal.

At the same time, the large negative values $g_{N C}(r)$ (see Figure 6(b)) as indicating cluster localization of quasi-molecular bonds for lead 9\%-solution in liquid sodium only 1.2 times more than in the 6\%-solution that specifies the growth of clusters at increasing lead concentration.

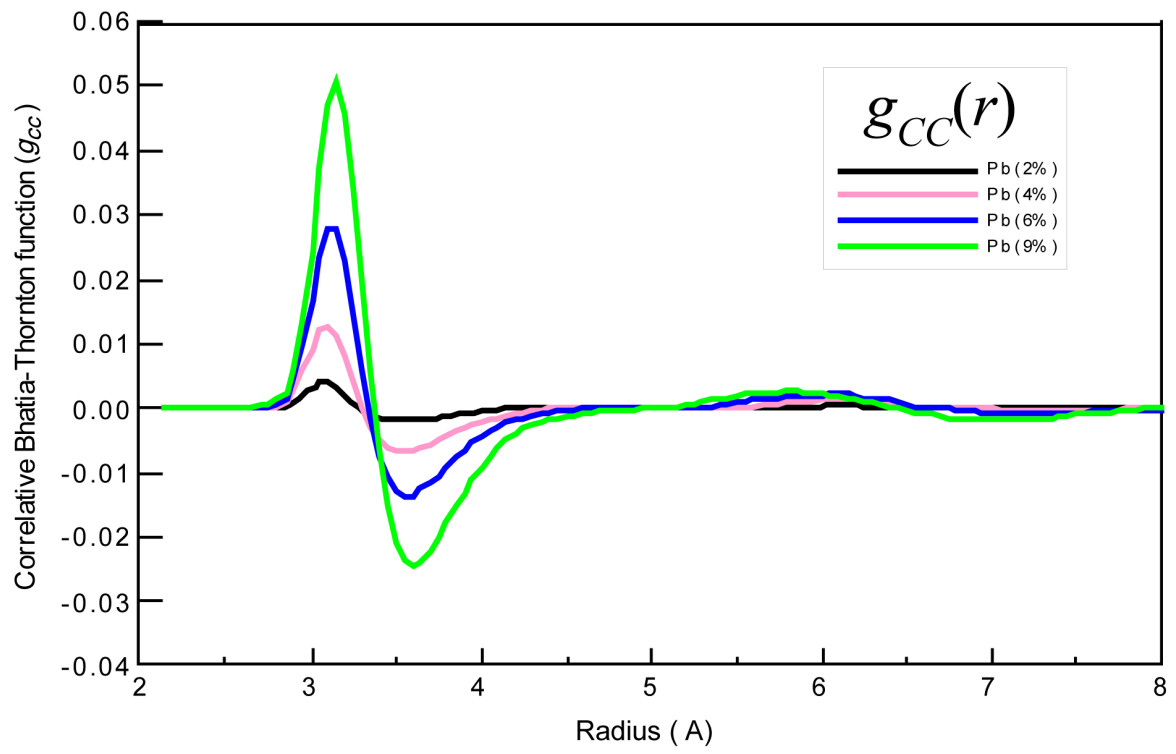

(a)

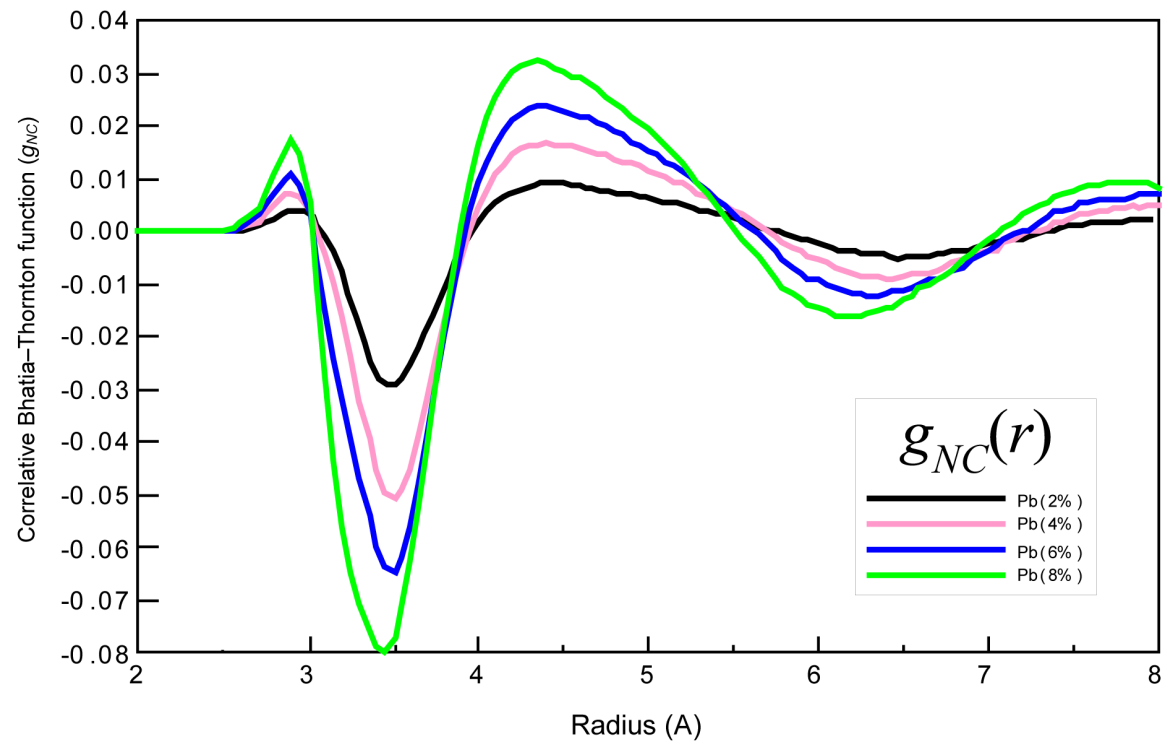

(b)

Figure 6. The correlative Bhatia-Thornton functions (9) for four compositions of $\mathrm{Na}_{1-x} \mathrm{~Pb}_{x}$ alloy as composition fluctuations (a) and cross-correlations between density and composition fluctuations of the melt (b) at $698 \mathrm{~K}$ for Fi(I)-HA model of sodium and lead pair potentials. 
So, it follows from results of MD simulating $\mathrm{Na}_{1-x} \mathrm{~Pb}_{x}$ melt for $0.01<x<0.10$ that lead impurity in liquid sodium is characterized by the micro-non-homogeneous state as compound clusters of variable composition in the liquid matrix of sodium. Just therefore the binary system, $\mathrm{Na}_{1-x} \mathrm{~Pb}_{x}$, in this interval of lead concentration has no eutectic which is to be found in the range of $0<x<0.01$ if it is generally on sodium side of this phase diagram.

One will talk about that below. Here, we notice that binary melt, $\mathrm{Na}_{1-x} \mathrm{~Pb}_{x}$, at $x<0.01$ will not possess enough inhibitive ability for auto-quenching sodium fires. Therefore its usage as a coolant of fast reactors is not interested.

For the binary melt, $\mathrm{Na}_{0.95} \mathrm{~Pb}_{0.05}$, its usage as a coolant will have technological difficulties caused by stratification of such the alloy on different micro-phases at solidification. The subsequent melting such the mixture will be accompanied by forming a viscous suspension which complicates the coolant operation at the stage of full dissolution in sodium of solid compound micro-particles $\left(\mathrm{Na}_{15} \mathrm{~Pb}_{4}\right)_{\mathrm{n}}$. Therefore it is reasonable finding an alternative melt for $\mathrm{Na}_{0.95} \mathrm{~Pb}_{0.05}$ which would have eutectics near this composition.

\section{Diluted Solution of Lead in Liquid Sodium}

The phase diagram of $\mathrm{Na}_{1-x} \mathrm{~Pb}_{x}$ is investigated multiply but the diluted $(x \ll 1)$ one is not studied for some reason. As shown in [26], the liquidus of this system at $x<0.07$ is not determined due to lack of experimental data. According to [27], the system, $\mathrm{Na}_{1-x} \mathrm{~Pb}_{x}$, at $x \sim 0.001$ has the eutectic. At more values of $x$, the liquidus temperature grows sharply at first and then smoothly up to a border of studied range at $7.8 \%$ as shown in Figure 7.

One can see that the liquidus curve at $0.1 \%$ of lead content is broken that is interpreted by authors of [27] as a eutectic. The liquidus temperature at $x \geq 0.066$ in [27] coincides with the data of [28] obtained for lead concentration in liquid sodium in the range of $6.6 \%-20.0 \%$.

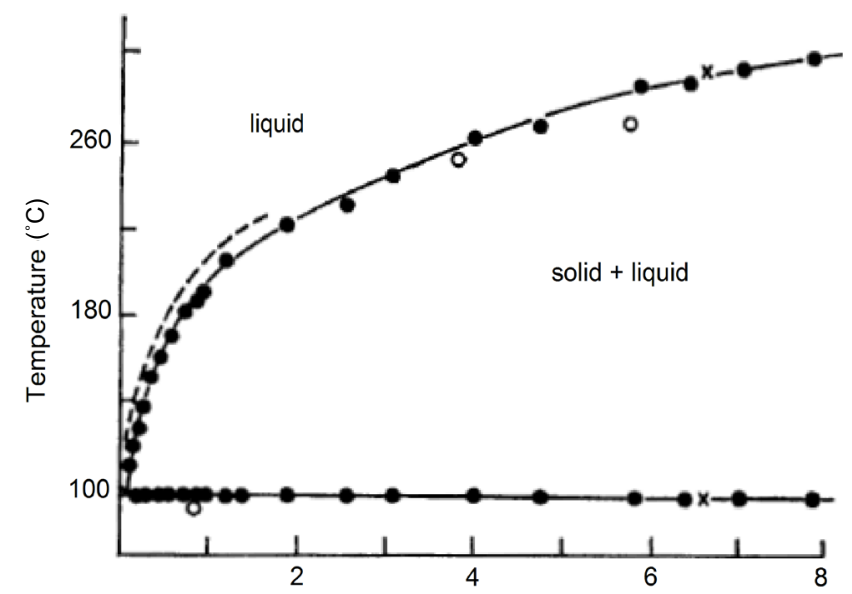

(a)

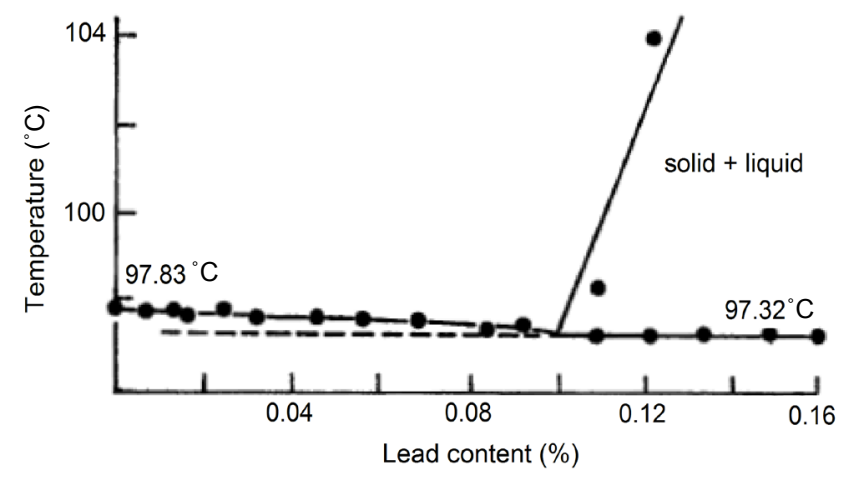

(b)

Figure 7. The phase diagram of Pb-Na system on sodium side (a) and its details (b) below $0.16 \%$ of lead concentration in liquid sodium [27]. 
As opposed to lead, other elements of IV group of Periodic table don't form eutectics on sodium side of binary systems [29]. At the same time, solubility curves have a common form shown in Figure 8. The solubility of these elements in liquid sodium has exponential dependence on converse temperature [27] [29]:

$$
\ln x=\Delta H / R T+\Delta S / R
$$

where $R$ is the gaseous constant and $T$ is Kelvin temperature. Parameters $(\Delta H, \Delta S)$ of this equation for elements of IV group of Periodic table are presented in Table 2. The parameters of these elements solubility in liquid sodium have no basic distinctions. Hence, one can assume that lead demonstrates eutectic degeneracy on sodium side of phase $\mathrm{Na}-\mathrm{M}_{\mathrm{IV}}$ diagram (see Figure 5) and the impurity for significant eutectic, $\mathrm{Na}_{1-x} \mathrm{M}_{x}$ at $x>0.01$, is to be found among the elements of VI period from the left of IV group.

\section{Lean Solution of Heavy Metals in Liquid Sodium}

It is known [10] that the binary system, $\mathrm{Na}_{1-\chi} \mathrm{M}_{x}$, can have eutectic at $x \geq 0.01$ if impurity, $\mathrm{M}$, for example, thallium in sodium at $x<0.01$ forms a homogeneous introduction solution [9] and then makes polymorphic transition in the colloidal one. Its phase diagram in sodium [30] is shown in Figure 9. One can see that the system, $\mathrm{Na}_{1-\chi} \mathrm{Tl}_{\chi}$, has the simple eutectic at $x=0.071$ and melting point of $\sim 64^{\circ} \mathrm{C}$.

Thallium as a heavy metal (with atomic number of 81 , density of $11.85 \mathrm{~g} / \mathrm{cm}^{3}$, melting point of $304^{\circ} \mathrm{C}$, and the boiling one of $1473^{\circ} \mathrm{C}$ ) [31] belongs to main III subgroup in VI period of Periodic table. The content of this element in earth is about $0.7 \mathrm{mg} / \mathrm{kg}$ [32] and it consists of two stable isotopes: ${ }^{205} \mathrm{Tl}(70.5 \%)$ and ${ }^{203} \mathrm{Tl}(29.5 \%)$ [31]. First of them has a low neutron-capture cross-section ( 0.5 barn) as opposed to the second one ( 130 barn) [33].

Thus, the attention is merited by studying eutectic, $\mathrm{Na}_{0.929} \mathrm{Tl}_{0.071}$, which as modified sodium coolant with enriched isotope, ${ }^{205} \mathrm{Tl}$, can appear attractive for suppressing its chemical activity in environment due to thallium has this activity at iron level. It is on the one hand, and on the other, a high boiling point of thallium excludes its volatility from the sodium melt.

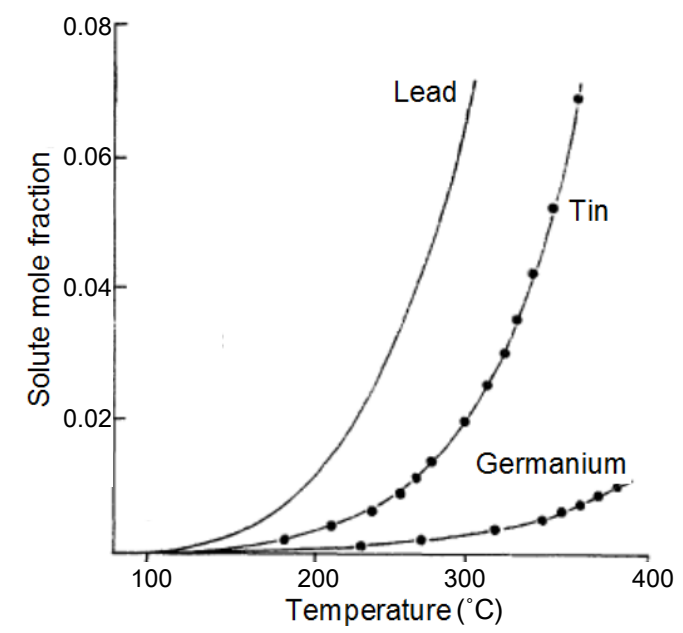

Figure 8. Temperature dependence of solubility in sodium for germanium, tin, and lead [29].

Table 2. Thermodynamic parameters of Periodic-table IV group elements for their solubility in liquid sodium.

\begin{tabular}{ccccccc}
\hline Element, $\mathrm{M}_{\mathrm{IV}}$ & Compound & $\Delta H, \mathrm{~kJ} / \mathrm{mol}$ & $\Delta S, \mathrm{~J} / \mathrm{mol} \cdot \mathrm{K}$ & $x$ range, $\%$ & $T, \mathrm{~K}$ & Ref. \\
\hline Carbon & $\mathrm{Na}_{2} \mathrm{C}_{2}$ & 104.5 & - & $0.00-0.10$ & $872-1223$ & {$[34]$} \\
& & 44.31 & 29.51 & $0.00-0.99$ & $371-653$ & {$[29]$} \\
Germanium & $\mathrm{NaGe}$ & 40.19 & 22.08 & $0.28-4.00$ & $573-823$ & {$[35]$} \\
& & 46.75 & 50.71 & $0.00-3.60$ & $371-594$ & {$[29]$} \\
\multirow{2}{*}{ Tin } & $\mathrm{Na}_{15} \mathrm{Sn}_{4}$ & 45.00 & 45.08 & $0.01-0.88$ & $373-533$ & {$[35]$} \\
Lead & $\mathrm{Na}_{15} \mathrm{Pbn}_{4}$ & 29.58 & 23.09 & $0.10-0.52$ & $371-443$ & {$[27]$} \\
\hline
\end{tabular}




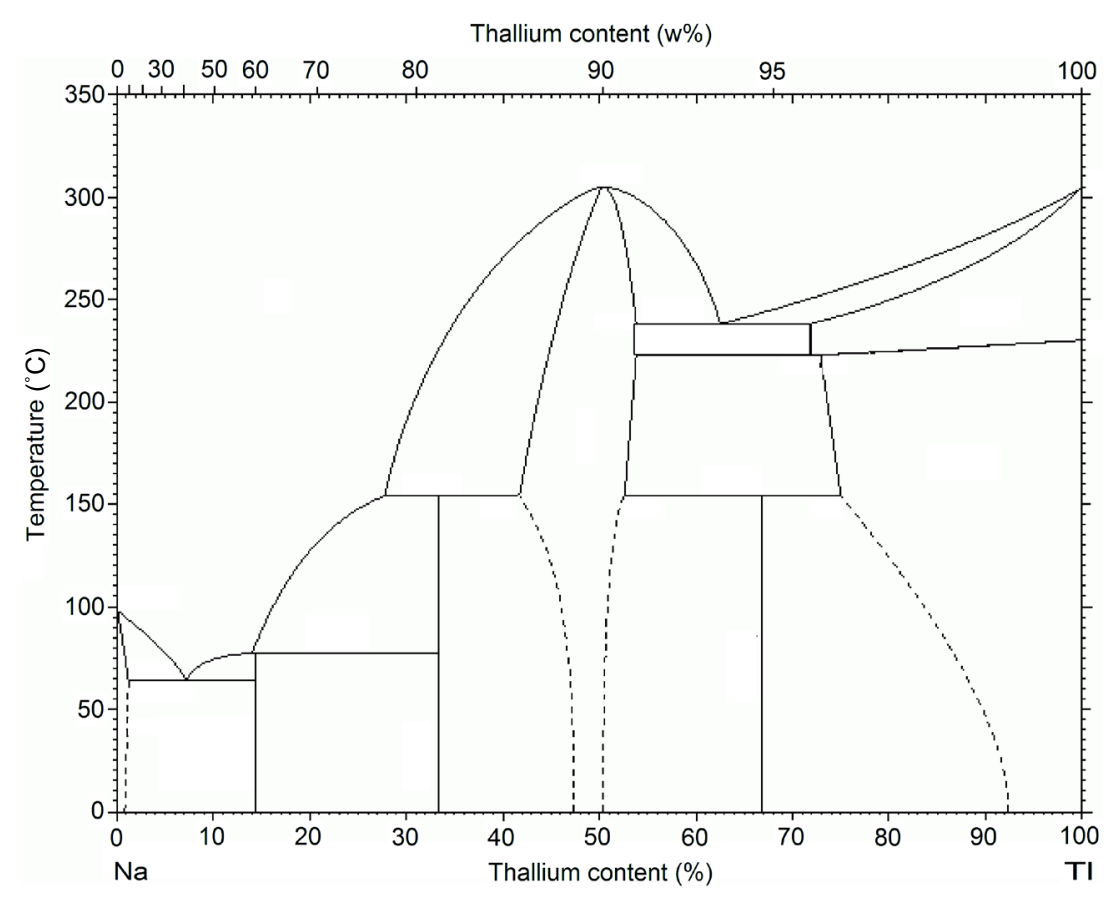

Figure 9. The phase diagram of system, Na-Tl [30].

\section{Conclusions}

It is specified that the minor additive (1\% - 10\%) of lead in liquid sodium is characterized by forming compound clusters with variable composition. Just therefore the binary systems Na-M $\mathrm{M}_{\mathrm{IV}}$ of sodium and elements from the periodic-table forth-group have no eutectics in this composition range and cannot be used as a modified sodium coolant due to changing its composition at solidification.

It is to find an alloy of sodium with another additive from adjacent groups which has a eutectic in this composition range, for example the simple eutectic of system, $\mathrm{Na}_{1-x} \mathrm{Tl}_{x}$, at $x=0.071$ with melting point of $\sim 64^{\circ} \mathrm{C}$. This molten alloy as sodium coolant with enriched isotope, ${ }^{205} \mathrm{Tl}$, can appear attractive for inhibiting its chemical activity of sodium because this alloy is to have protective clusters just as the lead alloyed one.

\section{Acknowledgements}

Authors thank the colleagues for helping this work and useful discussion of mainstream in developing a new approach to impurity modifying the sodium coolant and are pleased to the Russian Foundation for Basic Research for supporting this work (grant \# 12-08-12025-ofi-m).

\section{References}

[1] Hoshino, K. and Young, W.H. (1981) On the Entropy of Mixing of the Liquid Na-Pb Alloy. Journal of Physics F: Metal Physics, 11, L7. http://dx.doi.org/10.1088/0305-4608/11/1/002

[2] Matsunaga, S., Ishigura, T. and Tamaki, S. (1983) Thermodynamic Properties of Liquid Na-Pb Alloys. Journal of Physics F: Metal Physics, 13, 587. http://dx.doi.org/10.1088/0305-4608/13/3/009

[3] Van der Lugt, W. (1991) Zintl Ions as Structural Units in Liquid Alloys. Physica Scripta, 39, 372. http://dx.doi.org/10.1088/0031-8949/1991/T39/059

[4] Reijers, H.T.J. and Van der Lugt, W. (1990) Molecular-Dynamics Study of Liquid NaPb, KPb, RbPb, and CsPb Alloys. Physical Review B, 42, 3395. http://dx.doi.org/10.1103/PhysRevB.42.3395

[5] Senda, Y., Shimojo, F. and Hoshino, K. (1999) The Origin of the First Sharp Diffraction Peak in Liquid Na-Pb Alloys: Ab Iinitio Molecular-Dynamics Simulations. Journal of Physics: Condensed Matter, 11, 2199. http://dx.doi.org/10.1088/0953-8984/11/10/007

[6] Thakur, A., Negi, N.S. and Ahluwalia, P.K. (2005) Electrical Resistively of NaPb Compound-Forming Liquid Alloy 
Using Ab Initio Pseudo Potentials. Pramana-Journal of Physics, 65, 349. http://dx.doi.org/10.1007/BF02898622

[7] Subbotin, V.I., et al. (2002) Liquid-Metal Coolants for Nuclear Power. Atomic Energy, 92, 31. http://dx.doi.org/10.1023/A:1015050512710

[8] Shimkevich, A.L. and Shimkevich, I.Yu. (2011) Molecular Dynamics Simulation of the Clustering of Minor Lead Additives in Liquid Sodium. Journal of Metallurgy, 2011, Article ID: 890321. http://dx.doi.org/10.1155/2011/890321

[9] Shimkevich, A.L. (2008) The Composition Principles for Designing Nuclear-Reactor Materials. N.N. PonomarevStepnoi Edition, IzdAt, Moscow.

[10] Kolokol, A.S., Shimkevich, A.L. and Shimkevich, I.Yu. (2008) On Composition Converting Liquid Metal Alloys. Journal of Physics: Conference Series, 98, Article ID: 042021.

[11] Tegze, M. and Hafner, J. (1989) Electron Structure of Metallic and Semiconducting Alkali-Metal-Lead Compound. Physical Review B, 39, 8263-8274. http://dx.doi.org/10.1103/PhysRevB.39.8263

[12] Young, W.H. (1992) Structural and Thermodynamic Properties of NFE Liquid Metals and Binary Alloys. Reports on Progress in Physics, 55, 1769-863.

[13] Hafner, J., Pasturel, A. and Hicter, P. (1984) Simple Model for the Structure and Thermodynamics of Liquid Alloys with Strong Chemical Interactions. II. Chemical Order and Packing Constraints. Journal of Physics F: Metal Physics, 14, 2279.

[14] Saxena, N.S., et al. (1988) Phonon Dispersion in a Metallic Glass. Physical Review B, 38, 8093-8096.

[15] Ichimaru, S. and Utsumi, K. (1981) Analytic Expression for the Dielectric Screening Function of Strongly Coupled Electron Liquids at Metallic and Lower Densities. Physical Review B, 24, 7385-7388.

[16] Dzugutov, M., Larsson, K.E. and Ebbsjo, I. (1988) Pair Potential in Liquid Lead. Physical Review A, 38, 3609-3617.

[17] Dharma-Wardana, M.W.C., Aers, G.C., Jacobs, P.W.M., Rycerz, Z.A. and Larsson, K.E. (1988) Interionic Potentials, Pseudo Potentials and the Structure Factor of Liquid Lead. Physical Review A, 37, 4500-4503.

[18] Heine, V. and Abarenkov, I. (1964) A New Method for the Electronic Structure of Metals. Philosophical Magazine, 9, 451-465.

[19] Shaw, R.W. (1968) Optimum Form of a Modified Heine-Abarenkov Model Potential for the Theory of Simple Metals. Physical Review, 174, 769-781.

[20] Fiolhais, C., Perdew, J.P., Armster, S.Q., MacLaren, J.M. and Brajczewska, M. (1995) Dominant Density Parameters and Local Pseudo Potentials for Simple Metals. Physical Review B, 51, 14001-14011.

[21] Hesson, J.C., Shimotake, H. and Tralmer, J.M. (1968) Densities of Molten Sodium-Lead and Sodium-Bismuth Alloys. Journal of Metals, 20, 6.

[22] McAlister, S.P. (1972) The Compressibility of Liquid Sodium Alloys. Philosophical Magazine, 26, 853-863. http://dx.doi.org/10.1080/14786437208226961

[23] Busse-Machukas, V.B. and Morachevsky, A.G. (1986) Density of Liquid Alloys for Systems of Lead-Sodium and Lead-Potassium. Color Metallurgy, N4, 33.

[24] Matsunaga, S. and Tamaki, S. (1983) Compound-Forming Effect in the Resistivity of Liquid Na-Pb Alloys. Journal of the Physical Society of Japan, 52, 1725-1729. http://dx.doi.org/10.1143/JPSJ.52.1725

[25] Lamprecht, G.J., Dicks, L. and Crowther, P. (1968) The Pb-Na Phase Diagram. The Journal of Chemical Physics, 72, $1439-1441$.

[26] Hansen, M. (1958) Constitution of Binary Alloys. 2nd Edition, McGraw-Hill, New York.

[27] Hubberstey, P. and Pulham, R.J. (1972) The Sodium-Lead Phase Diagram. Journal of the Chemical Society, Dalton Transactions, N7, 819-821. http://dx.doi.org/10.1039/dt9720000819

[28] Mathewson, C.H. (1906) Metallographische Mitteilung aus dem Institut fur Anorganische Chemie der Universitut Guttingen. XXXIV. Natrium-Blei, Natrium-Kadmium, Natrium-Wismut und Natrium-Antimonlegierungen. Zeitschrift für Anorganische und Allgemeine Chemie, 50, 171-198.

[29] Hubberstey, P. and Pulham, R.J. (1974) Solubility of Tin and Germanium in Liquid Sodium: The Sodium-Tin Partial Phase Diagram. Journal of the Chemical Society, Dalton Transactions, N14, 1541-1544. http://dx.doi.org/10.1039/dt9740001541

[30] Grube, G. and Schmidt, A. (1936) The Na-Tl Phase Diagram. Zeitschrift für Elektrochemie, 42, 201-209.

[31] http://en.wikipedia.org/wiki/Thallium

[32] Guberman, D.E. (2010) Mineral Commodity Summaries 2010: Thallium. United States Geological Survey, 2010-0513.

[33] (1976) Tables of Physical Constants, Handbook. I.K. Kikoin Edition, AtomIzdat, Moscow. 
[34] Longson, B. and Thorley, A.W. (1970) Solubility of Carbon in Sodium. Journal of Applied Chemistry, 20, $372-379$. http://dx.doi.org/10.1002/jctb.5010201203

[35] Hubberstey, P. and Castleman, A.W. (1972) Thermodynamic Properties of Solutions of Group IV Metals Dissolved in Liquid Sodium: I. Sodium-Lead and Sodium-Germanium Solutions. Journal of the Electrochemical Society, 119, 963966. http://dx.doi.org/10.1149/1.2404377 
Scientific Research Publishing (SCIRP) is one of the largest Open Access journal publishers. It is currently publishing more than 200 open access, online, peer-reviewed journals covering a wide range of academic disciplines. SCIRP serves the worldwide academic communities and contributes to the progress and application of science with its publication.

Other selected journals from SCIRP are listed as below. Submit your manuscript to us via either submit@scirp.org or Online Submission Portal.
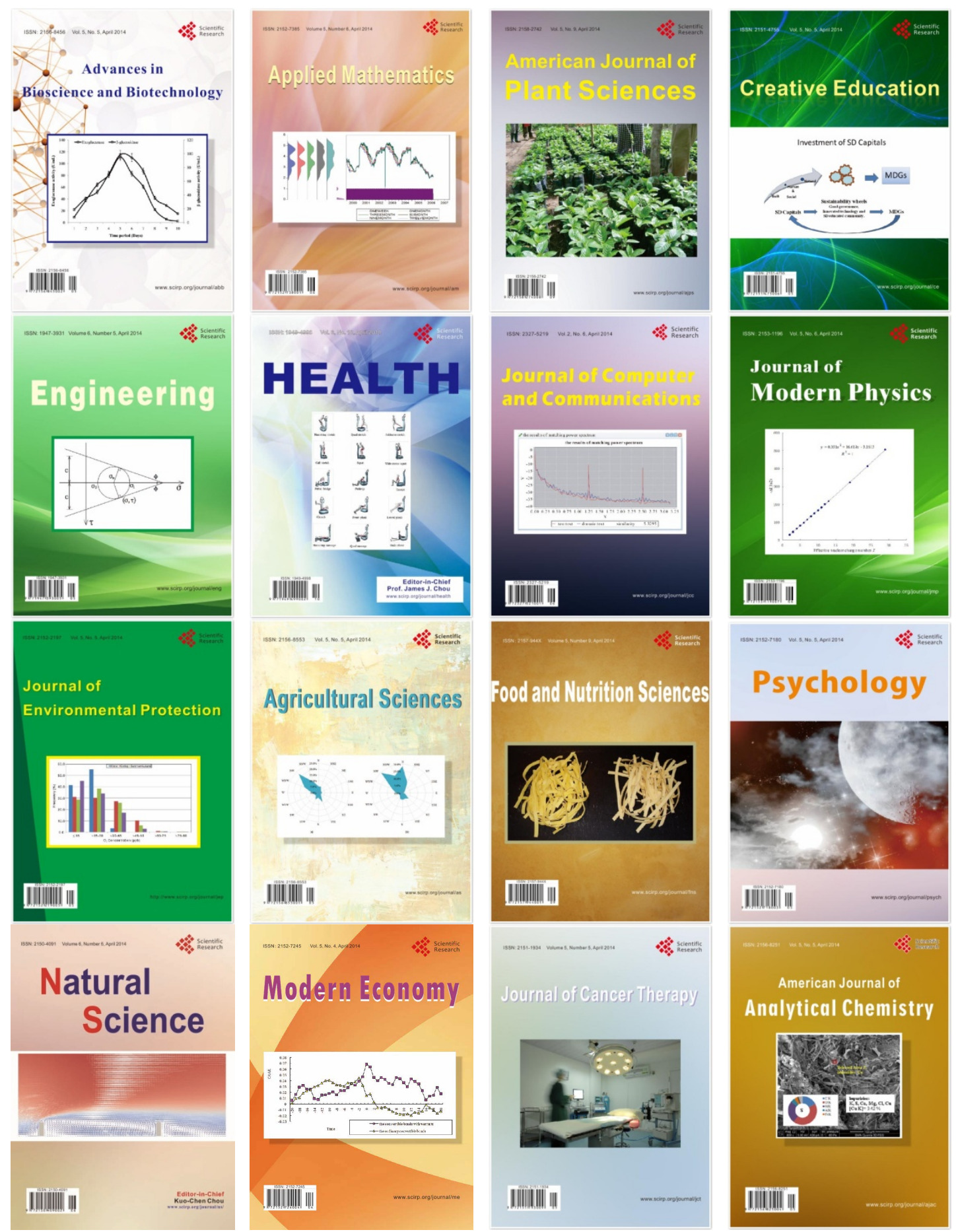